\title{
Chrysopogon zizanioides aqueous extract mediated synthesis, characterization of crystalline silver and gold nanoparticles for biomedical applications
}

This article was published in the following Dove Press journal:

International Journal of Nanomedicine

2 July 2013

Number of times this article has been viewed

\section{Kantha D Arunachalam Sathesh Kumar Annamalai \\ Center for Environmental Nuclear Research, Directorate of Research, SRM University, Chennai, Tamil Nadu, India}

\begin{abstract}
The exploitation of various plant materials for the biosynthesis of nanoparticles is considered a green technology as it does not involve any harmful chemicals. The aim of this study was to develop a simple biological method for the synthesis of silver and gold nanoparticles using Chrysopogon zizanioides. To exploit various plant materials for the biosynthesis of nanoparticles was considered a green technology. An aqueous leaf extract of $C$. zizanioides was used to synthesize silver and gold nanoparticles by the bioreduction of silver nitrate $\left(\mathrm{AgNO}_{3}\right)$ and chloroauric acid $\left(\mathrm{HAuCl}_{4}\right)$ respectively. Water-soluble organics present in the plant materials were mainly responsible for reducing silver or gold ions to nanosized $\mathrm{Ag}$ or $\mathrm{Au}$ particles The synthesized silver and gold nanoparticles were characterized by ultraviolet (UV)-visible spectroscopy, scanning electron microscopy (SEM), energy dispersive X-ray analysis (EDAX), Fourier transform infrared spectroscopy (FTIR), and X-ray diffraction (XRD) analysis. The kinetics decline reactions of aqueous silver/gold ion with the $C$. zizanioides crude extract were determined by UV-visible spectroscopy. SEM analysis showed that aqueous gold ions, when exposed to the extract were reduced and resulted in the biosynthesis of gold nanoparticles in the size range $20-50 \mathrm{~nm}$. This eco-friendly approach for the synthesis of nanoparticles is simple, can be scaled up for large-scale production with powerful bioactivity as demonstrated by the synthesized silver nanoparticles. The synthesized nanoparticles can have clinical use as antibacterial, antioxidant, as well as cytotoxic agents and can be used for biomedical applications.
\end{abstract}

Keywords: nanoparticles, bioreduction, SEM, silver, gold

\section{Introduction}

The synthesis of metal and semiconductor nanoparticles is an important topic of research because of their potential applications in catalysis, biosensing, recording media, and optoelectronics. ${ }^{1}$ The chemical methods follow electrochemical, thermal, laser, microwave, polyol, radiolytic, sonochemical, and various other techniques. ${ }^{2}$ Currently, there is a growing need to develop an environmentally benign nanoparticle synthesis that does not use toxic chemicals in the synthesis protocols to avoid adverse effects in medical applications.

The properties of noble metal nanoparticles such as silver and gold have previously been changed with many stabilizing and capping agents for various applications. The biological means of synthesizing nanoparticles provides an edge over chemical means as it is cost-effective, does not involve physical barriers for lessening agents, and expels the toxic effects of the chemicals used for the synthesis. There are several plants that have been identified to synthesize nanoparticles and the rate of synthesis of 
nanoparticles by plant extracts is comparable to those of chemical methods and faster than green synthesis by microorganisms. ${ }^{3,4}$

Following our previous studies for the green synthesis of nanoparticles using Memecylon edule 5 and M. umbellatum $^{13}$ aqueous extract, attempts were made to synthesize silver nanoparticles (SNPs) and gold nanoparticles (GNPs) by green technology from medicinal plants. ${ }^{5}$ Until today, no reports have been available on the synthesis of SNPs and GNPs using aqueous leaf extracts of Chrysopogon zizanioides, a tropical medicinal plant originating from India and belonging to the Poaceae family. ${ }^{6}$

C. zizanioides (vetiver) is a perennial grass commercially used to extract fragrance oils and its medicinal properties. The name "vetiver" is drawn from the Tamil word "vettiver" and the South India peninsula is considered to be the center of origin from where vetiver is said to have spread over the world because of its value as a producer of aromatic oil. Vetiver is known to have been in use in India both for its fragrant oil and as a traditional medicine since antiquity, ${ }^{7}$ and its hedges have been applied for contour protection in India for centuries. ${ }^{8}$

Silver has been used in the form of metallic silver, silver nitrate, or silver sulfadiazine to treat burns, wounds, and severe bacterial infections. ${ }^{9,10}$ The synthesized silver ions have been used in many kinds of formulations. Recently, it was shown that hybrids of SNPs with amphiphilic hyperbranched macromolecules display effective antimicrobial surface coatings. The most important applications of SNPs and GNPs are in the medical industry, such as topical ointments to prevent infection in burns and open wounds. ${ }^{9}$

Similarly, GNPs have been considered as an important area of research because of their unique and tunable surface plasmon resonance (SPR) and their applications in biomedical science including drug delivery, tissue or tumor imaging, photo thermal therapy, and immune chromatographic identification of pathogens in clinical specimens. ${ }^{11}$ The GNPs are used for developing biosensors, DNA labelling, and vapor sensing. ${ }^{12}$

In this study, we show that an aqueous leaf extract of C. zizanioides, placed in a concentrated aqueous solution of $\mathrm{AgNO}_{3}$ and $\mathrm{HAuCl}_{4}$, resulted in reduction of the silver and gold ions to form SNPs and GNPs. These green-synthesized SNPs (GSNPs) and green-synthesized GNPs (GGNPs) of C. zizanioides were examined by ultraviolet-visible (UV-vis) spectroscopy, scanning electron microscopy (SEM), energy dispersive X-ray analysis (EDAX), Fourier transform infrared spectroscopy (FTIR), and X-ray diffraction (XRD) analysis for size and shape.

\section{Materials and methods Collection of plants}

The plants C. zizanioides were collected from Villupuram, Tamil Nadu, India, the herbarium was prepared for authentication, and taxonomic identification was done by Dr Jayaraman, Madras Christian College, Tambaram, Chennai, Tamil Nadu. The voucher specimen was numbered and kept in our research laboratory for further reference.

\section{Preparation of aqueous extract}

The leaves of $C$. zizanioides were first washed with distilled water to remove the dirt and further washed with mild soap solution and rinsed thrice with distilled water. The leaves were blotted with tissue paper and shade dried at room temperature for at least 2 weeks. After complete drying, the leaves were cut into small pieces and powdered in a mixer and sieved using a $20 \mu$ mesh sieve to get a uniform size range for use in further studies. The $20.0 \mathrm{~g}$ of the sieved leaf powder was added to $100 \mathrm{~mL}$ of sterile distilled water in a $500 \mathrm{~mL}$ Erlenmeyer flask and boiled for 5 minutes. The flasks were kept under continuous dark conditions at $30^{\circ} \mathrm{C}$. The extract was filtered and stored in an airtight container and protected from sunlight for further use.,13

\section{Phytochemical activity}

The qualitative phytochemical analyses of C. zizanioides extracts were performed following the methods of Parekh and $\mathrm{Chanda}^{14}$ to determine the presence of alkaloids (Mayer's, Wagner, Dragendorff's), flavonoids (alkaline reagent, Shinoda), phenolics (lead acetate, alkaline reagent test), triterpenes (liberman-burchard test), saponins (foam test), and tannins (gelatine).${ }^{15}$ The results were qualitatively expressed as positive $(+)$ or negative $(-) .{ }^{16}$ The chemicals used for the study were purchased from Sigma-Aldrich (Chennai, India).

\section{Synthesis of SNPs and GNPs}

Silver nitrate $\left(\mathrm{AgNO}_{3}\right)$ and chloroauric acid $\left(\mathrm{HAuCl}_{4}\right)$ from Sigma-Aldrich (St Louis, MO, USA) and the aqueous leaf extract of C. zizanioides were used for the bioreduction synthesis of nanoparticles. Five milliliters of aqueous leaf extract of C. zizanioides was added to $10 \mathrm{~mL}$ of $1 \mathrm{mM}$ aqueous $\mathrm{AgNO}_{3}$ and $\mathrm{HAuCl}_{4}$ solution in $250 \mathrm{~mL}$ Erlenmeyer flasks and incubated in a Rotary shaker at $150 \mathrm{rpm}$ in dark. The color change in the colloidal solutions occurred, showing the formation of SNPs and GNPs. ${ }^{5,17-19}$

\section{UV-Vis absorbance spectroscopy analysis}

The bioreduction (by $\mathrm{AgNO}_{3}$ or $\mathrm{HAuCl}_{4}$ ) of nanoparticles was recorded periodically using a UV-Vis $3000+$ double beam 
spectrophotometer (LabIndia, Maharashtra, India), which had slit widths of $0.5,1.0,2.0$, and $5.0 \mathrm{~nm}$. The samples were diluted with $2 \mathrm{~mL}$ of deionized water and measured by UV-Vis spectrum at regular time intervals. ${ }^{20}$ The deionized water was used as a blank for background correction of all UV-VIS spectra. All samples were loaded into a $1 \mathrm{~cm}$ path length quartz cuvette for sampling. The UV-Vis spectrometric readings were scanned from 200 to $800 \mathrm{~nm}$ and recorded at a scanning speed of $0.5 \mathrm{~nm}$ interval. The UV-VIS spectra were fit with Gaussian curves correcting for a cubic background for full-width at half maximum (FWHM) and wavelength of maximum absorbance measurements. The Gaussian fits to the UV-VIS spectra all had goodness of fit values $\left(\chi^{2} \sim 1\right)$, showing accurate curve analysis. ${ }^{17}$

\section{SEM analysis of SNPs and GNPs}

The prepared SNPs and GNPs were characterized using high resolution SEM analysis (JSM-5600 LV; JEOL, Tokyo, Japan). The samples were prepared by a simple drop coating of suspended silver or gold solution on to an electrically heated clean glass and allowing the solvent (water) to evaporate. The samples were left to dry at room temperature. ${ }^{21-23}$

\section{FTIR spectroscopy analysis of dried biomass after bioreduction}

To identify the biomolecules present in the leaf extract of C. zizanioides and the biomolecules within the SNPs and GNPs after synthesis, a carefully weighed quantity of the synthesized nanoparticles were subjected to FTIR analysis (PerkinElmer RX1; PerkinElmer, Waltham, MA, USA). ${ }^{24}$ The bioreduced chlorauric and silver solutions were centrifuged at 10,000 rpm for 15 minutes, and the pellets were washed three times with $20 \mathrm{~mL}$ of deionized water. ${ }^{25}$ The resulting purified suspensions were dried and ground with $\mathrm{KBr}$ pellets and analyzed by FTIR. The FTIR were recorded in the range of $400-4000 \mathrm{~cm}^{-1}$. To obtain a good signal and noise ratio, 512 scans were recorded. ${ }^{26}$

\section{EDAX spectrum measurements}

EDAX analysis to confirm elemental silver was carried out for the detection of elemental silver. The samples were dried at room temperature and then analyzed for sample composition of the synthesized nanoparticles. The elemental composition of the synthesized nanoparticles by $C$. zizanioides were dried, drop coated on to carbon film, and tested using EDAX analysis (S-3400 N; Hitachi, Tokyo, Japan). ${ }^{27,28}$

\section{XRD measurement}

To characterize the purified SNPs and GNPs, XRD measurements were conducted using an XRD-6000 X-ray diffractometer (Shimadzu, Kyoto, Japan) operated at a voltage of $40 \mathrm{kV}$ and $30 \mathrm{~mA}$ with $\mathrm{Cu} \mathrm{K} \alpha$ radiation in $\theta-2 \theta$ configurations. The crystallite domain size was calculated from the width of the XRD peaks by assuming that they were free from nonuniform strains using the following Scherer formula, ${ }^{29}$

$$
D=\frac{0.94 \lambda}{\beta \cos \theta}
$$

where $\mathrm{D}$ is the average crystallite domain size perpendicular to the reflecting planes, $\lambda$ is the $X$-ray wavelength, $\beta$ is the FWHM, and $\theta$ is the diffraction angle. ${ }^{19,30,31}$ To expel the added instrumental broadening, the FWHM was corrected using the FWHM from a large-grained Si sample.

$$
\beta_{\text {corrected }}=\left(\mathrm{FWHM}_{\text {sample }}^{2}-\mathrm{FWHM}_{\mathrm{si}}^{2}\right)^{1 / 2}
$$

This modified formula is valid only when the crystallite size is smaller than $100 \mathrm{~nm}^{24}$

\section{Results}

\section{Phytochemical screening}

The aqueous extract of $C$. zizanioides was evaluated for the presence of phyto constituents by qualitative chemical tests. The distinct phytochemicals that were present are shown in Table 1. The results infer the presence of terpinoids, alkaloids, flavonoids, triterpines, and tannins in the aqueous extract of $C$. zizanioides.

\section{Synthesis of SNPs and GNPs}

The GSNPs and GGNPs displayed yellowish-brown and ruby red color, respectively, in water; these colors arose

Table I Preliminary phytochemical investigation of aqueous extract of $C$. zizanioides

\begin{tabular}{ll}
\hline Phytochemicals & Aqueous extract \\
\hline Alkaloids & + \\
Phytosterol & + \\
Saponins & - \\
Tannins & + \\
Catechins & - \\
Flavonoids & + \\
Quinones & - \\
Triterpines & + \\
Steroids & - \\
\hline
\end{tabular}

Notes: +, present; -, absent. 


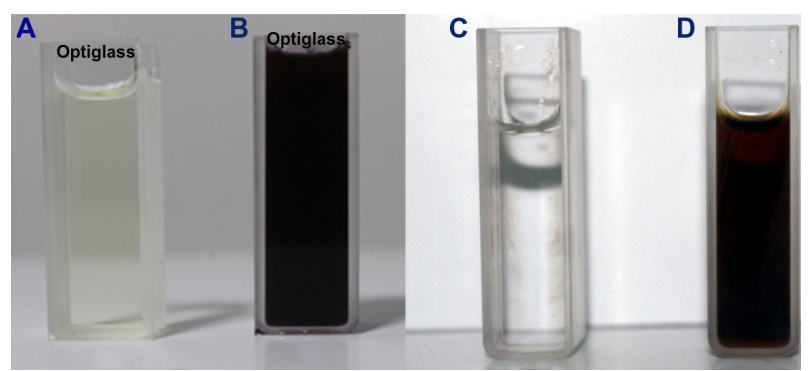

Figure I Synthesis of silver and gold nanoparticles.

Notes: (A) $\mathrm{AgNO}_{3}$; (B) synthesized silver nanoparticles in brown color solution after 24 hours; (C) $\mathrm{HAuCl}_{4}$ solution; (D) synthesized gold nanoparticles in ruby red color after 24 hours.

because of exciting surface plasmon vibrations in the metal nanoparticles. The color change is attributed to the collective oscillation of free conduction electrons induced by an interacting electromagnetic field in metallic nanoparticles, which is called SPR. ${ }^{32}$

In the present study, the SNPs were synthesized rapidly within 20 minutes of the incubation period in the aqueous silver nitrate solution, which turned to a brown color in 30 minutes of adding leaf extract (Figure 1A and B). The intensity of the brown color increased in direct proportion to the incubation period because of the excited SPR effect and reduced $\mathrm{AgNO}_{3}{ }^{12}$ The control $\mathrm{AgNO}_{3}$ solution (without leaf extract) showed no change of color with time and our results are comparable with the previous study done using
Dillenia indica fruit extract ${ }^{33}$ and with our own results done using M. edule, ${ }^{5}$ Memecylon umbellatum ${ }^{13}$ and indigofera aspalathoides. ${ }^{46}$

The color of the reaction mixture on formation of GNPs changed to ruby red color from a colorless/straw color (Figure 1C and D). This color change from colorless/straw to ruby red was noticed within the first 2 hours of reaction time. This visibly confirmed the presence of GNPs in the solution and that $\mathrm{AuCl}_{4}^{-}$ions had been reduced to $\mathrm{Au}$ ions.

\section{UV-Vis spectrophotometer}

The silver ions immediately declined within 20 minutes, which may have been due to the presence of water soluble phytochemicals like alkaloids, phytosterols, tannins, flavonoids, and triterpines in the $C$. zizanioides plant extract. The reduction of silver and gold ions occurred rapidly and more than $90 \%$ of the reduction of silver and gold ions was completed within 8 hours (at 1 and $5 \mathrm{~mL}$ of plant extract, respectively) after adding the aqueous plant extract to the metal ion solutions. The comparatively slower reduction rate of silver ions relative to that of gold ions was most likely because of differences in the reduction potentials of the two metal ions, the redox potential being considerably lower for gold ions. The characteristic absorption peak at $420 \mathrm{~nm}$ in UV-Vis spectrum (Figure 2) confirmed the formation of SNPs. SPR patterns, which detail the characteristics of metal

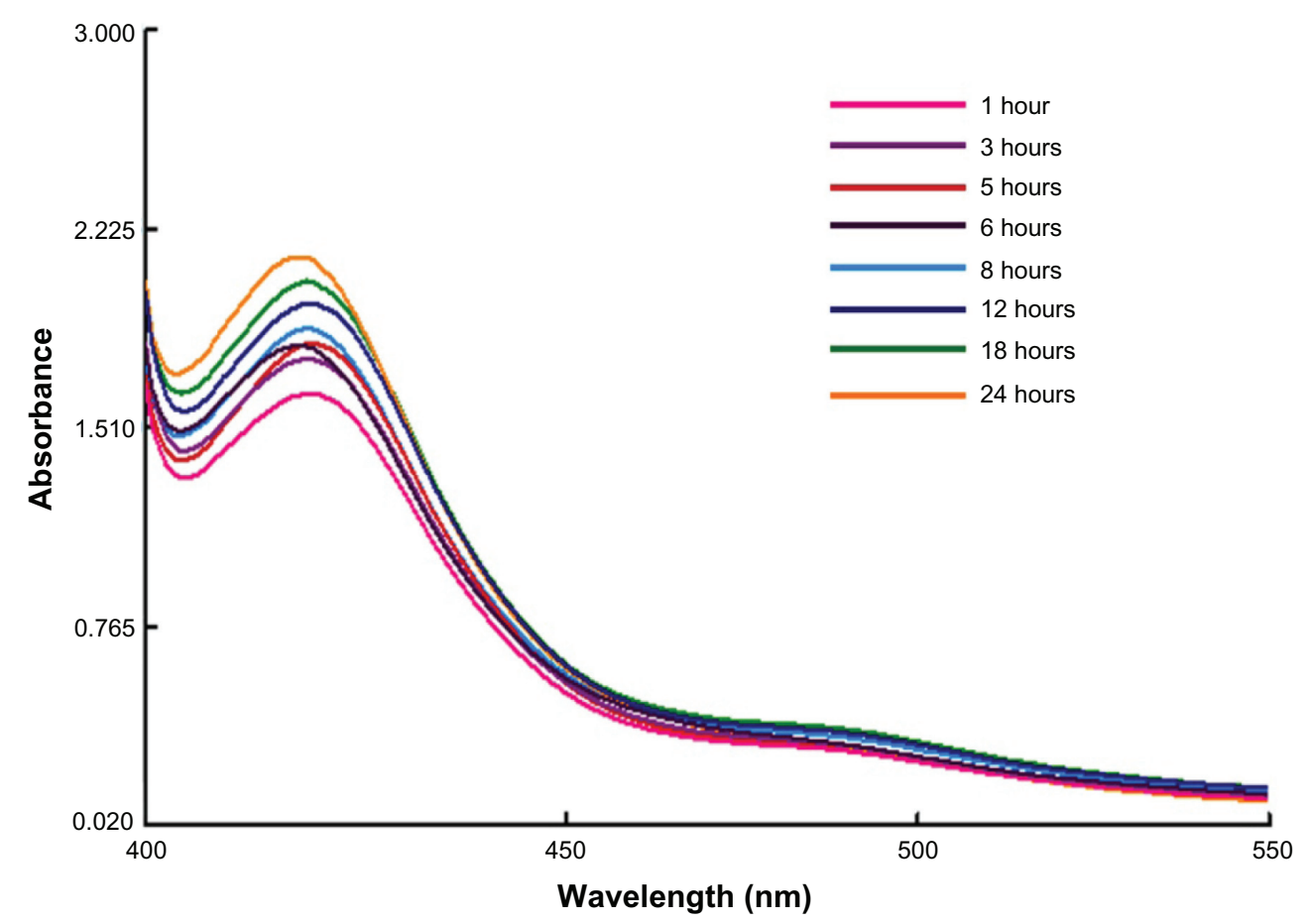

Figure 2 Time dependent absorption spectra of silver nanoparticles after the bioreduction of silver in the aqueous extract of Chrysopogon zizanioides. 


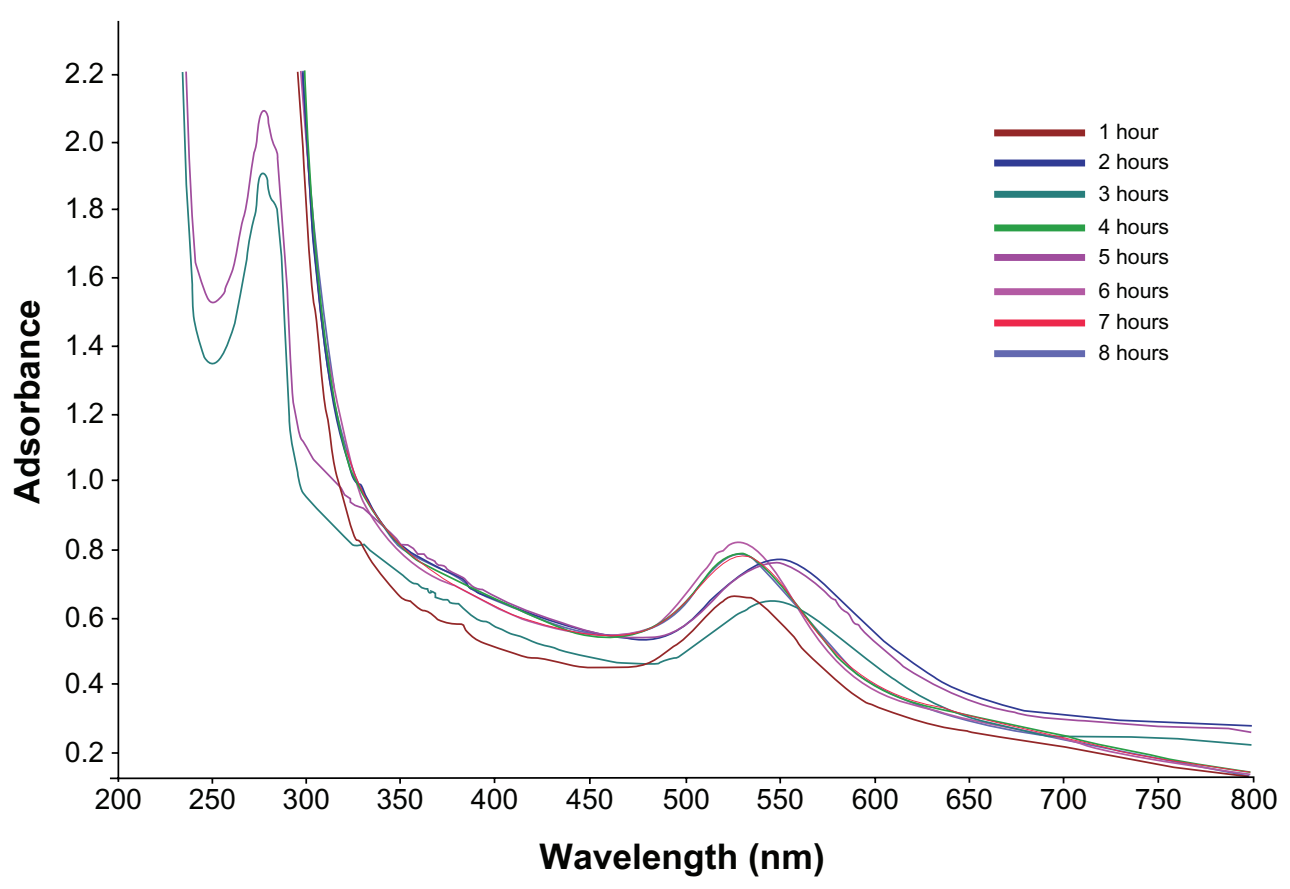

Figure 3 Time dependent absorption spectra of gold nanoparticles after the bioreduction with aqueous extract of Chrysopogon zizanioides.

nanoparticles, strongly depend on particle size, stabilizing molecules or the surface of adsorbed particles, and the dielectric constant of the medium. The nanoparticles showed an absorption peak around $420 \mathrm{~nm}$ after 1 hour of reaction, which is a characteristic SPR band of SNPs, possibly because of exciting longitudinal plasmon vibrations in the SNPs in the solution. ${ }^{33-35}$

The increase in the intensity of the ruby red color clearly suggests the formation of GNPs in the reaction mixture. The GGNPs were ruby red in the aqueous solution because of the exciting surface plasmon vibration of the GNPs at $540 \mathrm{~nm}$ (Figure 3). The kinetics of biosynthesis hastens with time and the intensity of the reaction mixture color increases rapidly. The process of biosynthesis is carried out at surrounding environmental conditions and the total reaction is completed within 8 hours. ${ }^{36}$

\section{SEM images of SNPs}

The SEM images clearly suggest that there was a thin layer of other material on the surface of the SNPs because of the capping silver ions. The SEM analysis of the bioreduced SNPs confirmed that the size of the metal particles was in the nano range and were roughly cubic in shape. The size of the SNPs was in the range of 85-110 nm after 24 hours and the representative SEM image is shown in Figure 4. Most of the nanoparticles was roughly cubic with flat edges. The size of the particles agreed with the noted SPR band. Some nanoparticles had isotropic nanostructures with irregular contours as shown in Figure 4; also most of the SNPs in the SEM images were in physical contact, but they were separated by a uniform interparticle distance. From our previous reports, it has been observed that the cubic shape of nanoparticles is synthesized after bioreduction. ${ }^{5,37}$

\section{SEM of GNPs}

A scanning electron microscope was employed to analyze the structure of the nanoparticles that were formed, as shown in Figure 5. The particles that formed were cubic in shape.

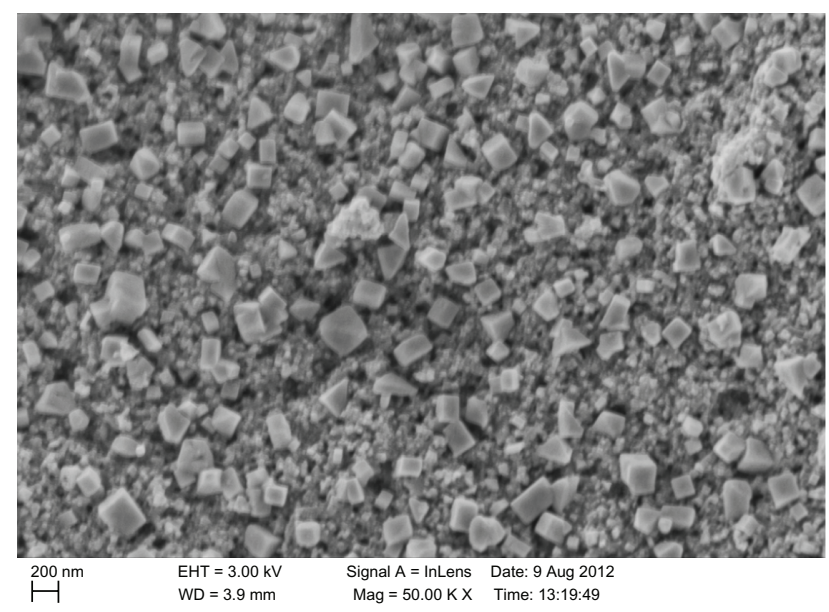

Figure 4 Scanning electron microscopy image of green silver nanoparticles synthesized by reduction of aqueous $\mathrm{AgNO}_{3}$ ions using Chrysopogon zizanioides extract. Abbreviations: EHT, extra high tension; Mag, magnification; WD, working distance. 


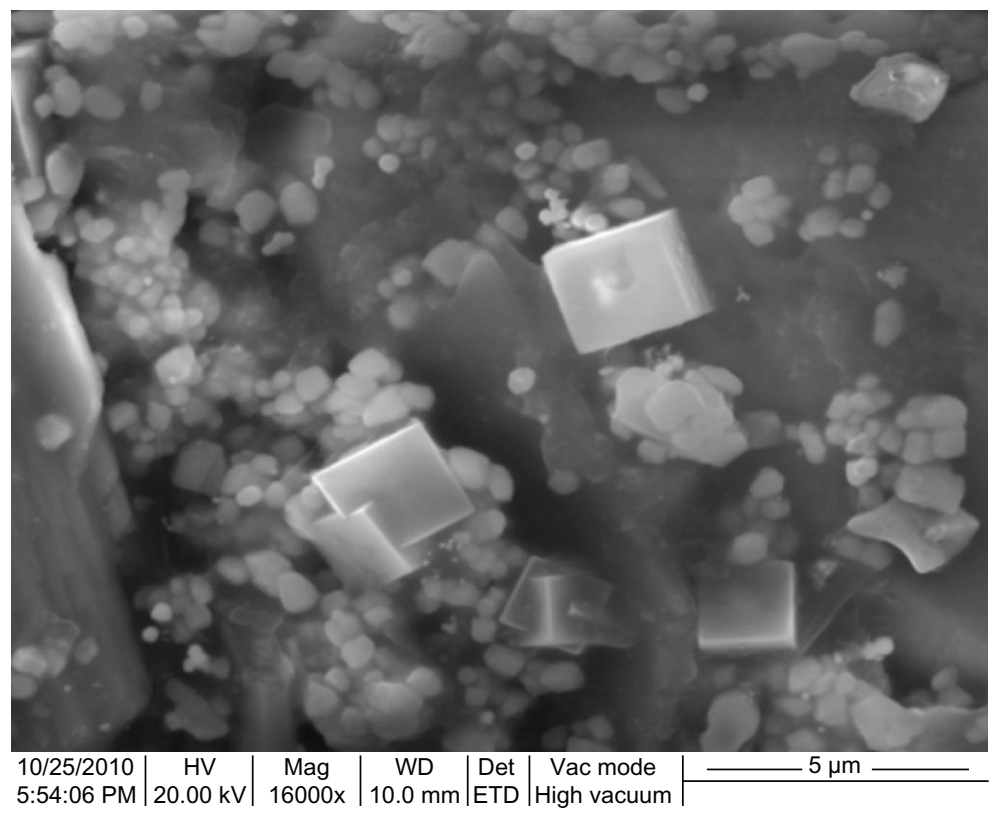

Figure 5 Scanning electron microscopy image of green gold nanoparticles synthesized by reducing aqueous $\mathrm{AuCl}_{4}^{-}$ions using Chrysopogon zizanioides extract. Abbreviations: Mag, magnification; WD, working distance; ETD, Everhart-Thornley detector; Vac, vacuum; HV, high voltage; Det, detector.

The cubic shaped nanoparticles that formed were shown to have high surface area and were in the range of 123-138 nm in size, with an average size of $130 \mathrm{~nm}$. The particles were monodispersed, with only a few particles of different size.

A high magnification SEM image recorded from our previous studies, showed that the biologically synthesized GNPs at the end of the reaction with $M$. edule leaf extracts were predominantly cubic in morphology. ${ }^{5,13,46}$ Low quantities of the extract can reduce the chloroaurate ions, but do not protect most of the quasi-spherical nanoparticles from aggregating because of the lack of biomolecules to act as protecting agents, which were clearly viewed from the SEM images.

\section{EDAX for SNPs}

The analysis through EDAX spectrometers confirmed the presence of the elementary silver signal of the SNPs, as shown in Figure 6. The vertical axis displays the number of X-ray counts, while the horizontal axis displays energy in $\mathrm{keV}$. The identification lines for the major emission energies for silver $(\mathrm{Ag})$ are displayed and they agree with the peaks in the spectrum, thus giving confidence that silver has been correctly identified. The EDAX spectrum clearly confirms that $93.8 \%$ was silver. The weak signals that arose at $0.5 \mathrm{keV}$ correspond to proteins or enzymes that are bound to the silver nanoparticle. There was also a strong signal at $0.24 \mathrm{keV}$ for $\mathrm{C}$ atom, which is due to the functional compounds present in aqueous plant extract. Individual cubic shaped SNPs using C. zizanioides are formed in the range of $2-4 \mathrm{keV}$. Similar signal energy peaks were also observed by other researchers. ${ }^{38,39}$
As reported from our earlier studies the EDAX pattern clearly shows the SNPs are crystalline in nature and showed strong signal energy peaks for silver atoms in the range of 2-4 $\mathrm{keV}$ with weaker signals for carbon, oxygen, and chloride, which were prevenient biomolecules of $M$. umbellatum, ${ }^{13}$ M. edule. ${ }^{5}$

\section{EDAX for GGNPs}

The GGNPs were further confirmed using EDAX spectrometry for the presence of gold with no other contaminants. The optical adsorption peak from Figure 7 was observed at nearly $4.60 \mathrm{keV}$, which is typical for the adsorption of gold nanocrystallites because of SPR. The current profile of EDAX of GGNPs of $C$. zizanioides showed strong gold atom signals around 4.60, 7.90, 9.65, and $13.63 \mathrm{keV}$. Similar peaks for GNPs synthesized from Trachy spermumammi and Papaver somniferum were observed by Vijayaraghavan et al, ${ }^{40}$ also

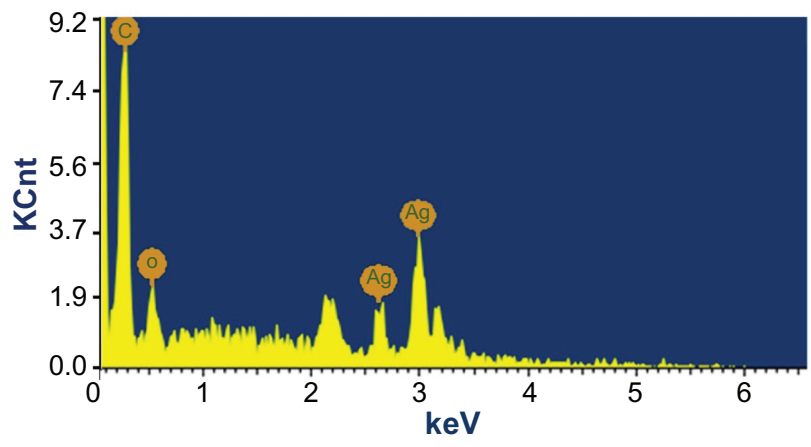

Figure 6 Energy dispersive $\mathrm{X}$-ray spectrum of silver $(\mathrm{Ag})$ nanoparticles. 


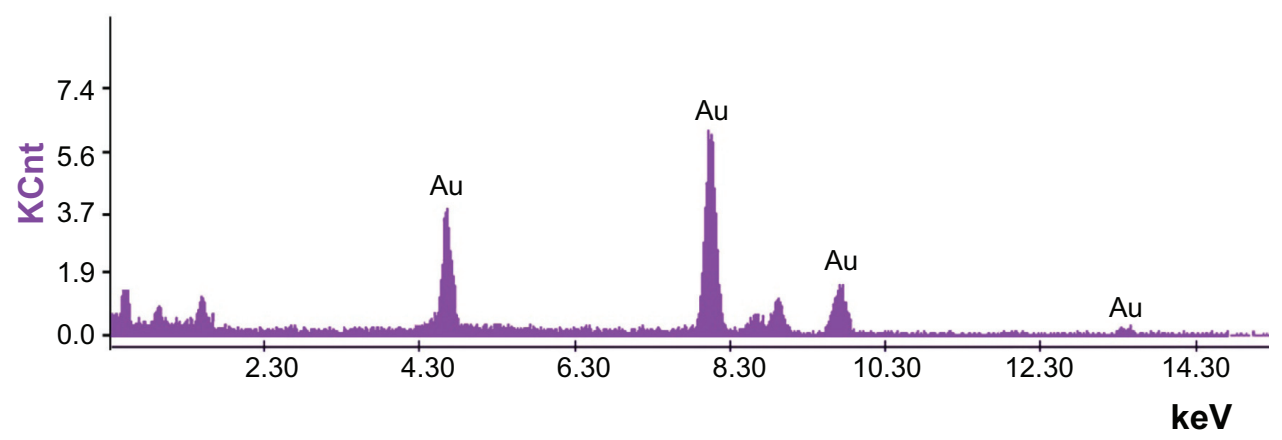

Figure 7 Energy dispersive X-ray spectrum of gold nanoparticles. Abbreviation: Au, gold.

for GNPs synthesized from Jatropha curcas by Bar et al. ${ }^{41}$ From our previous results, similar peaks for GNPs synthesis from M. edule and M. umbellatum were observed. ${ }^{5,13}$

\section{FTIR of SNPs and GNPs}

FTIR analysis was used to identify the possible biomolecules responsible for the reduction and capping on nanoparticle surfaces. In the present study, FTIR spectra of both the aqueous extract of $C$. zizanioides and synthesized SNPs and GNPs were recorded. FTIR measurements were carried out to identify the potential biomolecules in the $C$. zizanioides aqueous plant extract responsible for reducing the chloroaurate ions. It was noted the capping reagent responsible for the stability of the bioreduced GNPs involved the secondary amines.

The size distribution and characterization of the GSNPs was further corroborated by FTIR, as shown in Figure 8.
The interaction of nanoparticles with phytochemicals of $C$. zizanioides showed intensive peaks at 2884, 1600, 1507, 1387,1074 , and $1335 \mathrm{~cm}^{-1}$. Relative shifts in position and intensity distribution were confirmed with FTIR. This clearly shows that the oxidized polyphenols capped the surface of the nanoparticles and kept them stable for longer periods.

The FTIR for dry gold nanopowder of C. zizanioides showed strong bands at 2832, 1731, 1612, and $1403 \mathrm{~cm}^{-1}$. Similar peaks were also observed by other researchers. ${ }^{25,34,42}$

\section{XRD analysis of GSNPs and GGNPs}

The X-ray structural diffraction pattern of the GSNPs and GGNPs produced using the leaf extracts was proved and confirmed by the characteristic peaks observed in the XRD images for silver (Figure 9) and gold (Figure 10). The XRD

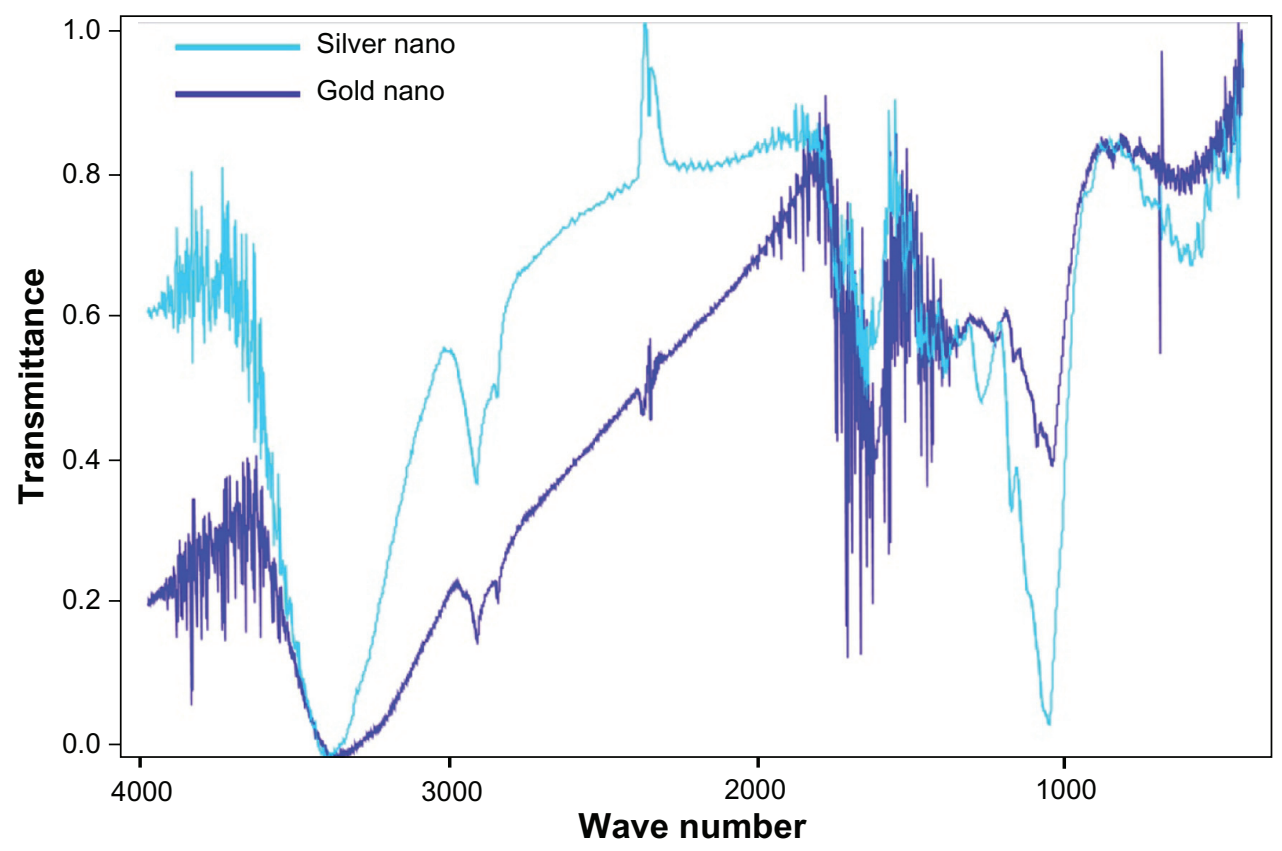

Figure 8 Fourier transform infrared spectroscopy spectrum of silver and gold nanoparticles. 


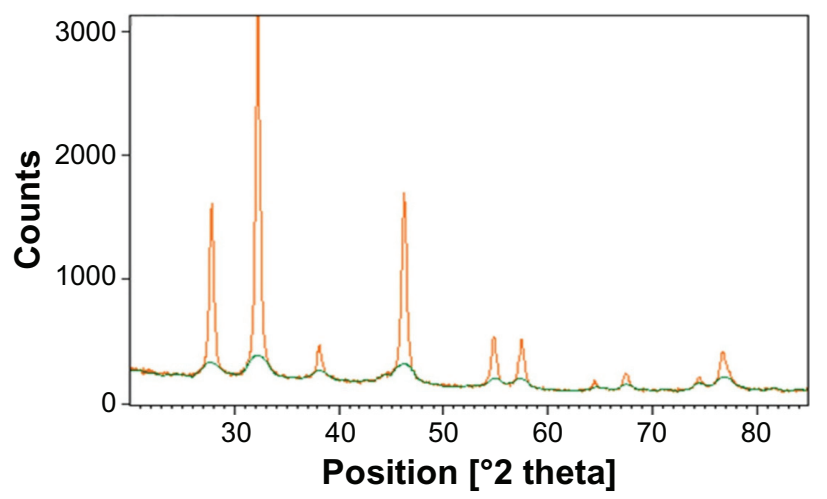

Figure 9 X-ray diffraction spectrum of green-synthesized silver nanoparticles.

pattern recorded for both SNPs and GNPs showed four intense peaks in the whole spectrum of $2 \theta$ values ranging from 20 to 80 . The XRD analysis showed distinct diffraction peaks at $24.08^{\circ}, 32.4^{\circ}, 38.5^{\circ}, 45.9^{\circ}, 55.2^{\circ}, 58.6^{\circ}, 64.02^{\circ}$, and $76^{\circ}$, which indexed the planes 111,200 , and 220 of the cubic face-centered silver; whereas any peaks originating because of potential silver oxide interference could not be observed and it could not be confirmed that the entire silver nitrate was converted to SNPs. The average grain size of the SNPs formed in the bioreduction was determined using the Scherrer equation

$$
\mathrm{d}=\left(0.9 \lambda \times 180^{\circ}\right) / \beta \cos \theta \pi
$$

and estimated as $105 \mathrm{~nm}$. The XRD pattern clearly explains the crystalline structure of the SNPs formed by green biosynthesis.

In comparing the XRD patterns of GSNPs and GGNPs, the content of the crystalline potassium chloride was significantly higher in the SNPs. The average crystallite size

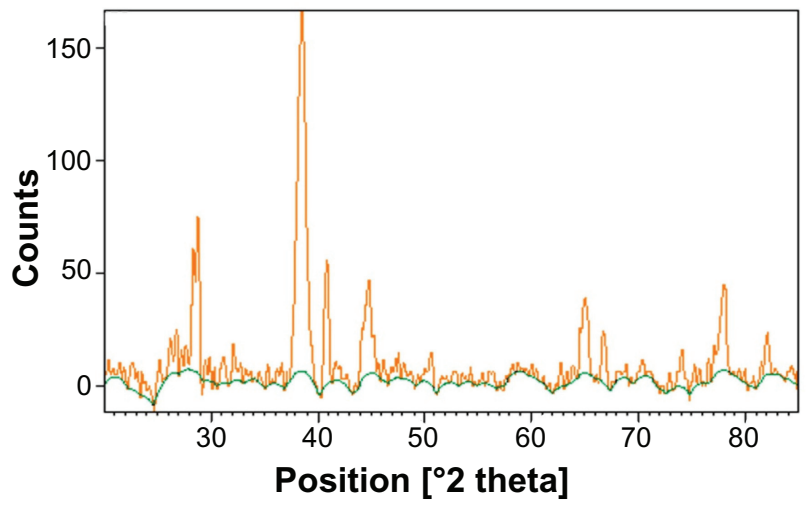

Figure 10 X-ray diffraction spectrum of green-synthesized gold nanoparticles. of the nanoparticles was estimated by the Scherrer equation and was found to be $105 \mathrm{~nm}$.

The GGNPs had phase peak positions corresponding to a highly crystalline potassium chloride phase. The XRD analysis showed higher distinct diffraction peaks at $38^{\circ}$ and $44^{\circ}$. Also, no other gold containing compounds other than the metallic gold could be recognized from the XRD pattern.

The crystallite sizes of the GGNPs were estimated by the Scherrer equation as $136 \mathrm{~nm}$. The elemental peaks found in the EDAX study agreed with the XRD results. ${ }^{43}$

\section{Conclusion}

Our results described a simple and eco-friendly timedependent method to biosynthesize green crystalline SNPs and GNPs in metal solution using medicinal plant extracts which does not need special physical conditions. Our research explained that $C$. zizanioides can be an excellent bioreductant and is an easily available, less expensive plant source for the synthesis of SNPs and GNPs. The C. zizanioides aqueous leaf extract is environmentally friendly and therefore this protocol could be used for the rapid production of SNPs. The size of GSNPs and GGNPs can be easily adjusted by varying the concentration of the leaf extract. The successful synthesis of SNPs and GNPs by reducing silver and gold ions using an aqueous extract of C. zizanioides leaves showed the reduction rate of silver ions was much faster than that of the gold ions. The water soluble compounds, like alkaloids and phytosterols, present in the C. zizanioides were mostly responsible for reducing silver and gold ions to nanosized silver and gold particles. The synthesized and well-studied green nanoparticles can be used for promising potential applications, including water purification, recording media, biosensing devices, nanoelectronics, and catalysis, as reported by Shukla et al. ${ }^{44}$ In one of our recent publications, we tissue engineered plant extracts by electrospinning, which makes it possible to combine the advantages of using these plant extracts in the form of nanofibrous mats to serve as skin graft substitutes or as nanofibrous wound dressings for the treatment of burns and wounds ${ }^{45}$ The synthesized SNPs and GNPs were well-capped and showed strong antibacterial activity (results not shown) which is very important for the aspects of its biomedical applications, such as a hydrogel dressing without any preservatives, which would be most efficient for cuts, new burns, and dry wounds. ${ }^{46}$ Other major applications that could be worthwhile are drug delivery, gene delivery, and biosensor applications where there is a direct contact of these nanoparticles with blood. ${ }^{47}$ This eco-friendly method for SNP 
and GNP biosynthesis does not use any chemicals and thus has the potential to be exploited in biomedical applications and will play an important role in future optoelectronic and biomedical applications. In our recent studies, we have conferred the ability of the silver nano particles for preventing biofilm in urinary catheters. ${ }^{48}$

\section{Acknowledgments}

The authors thank the support from the SRM University, Kattankulathur. The authors also thank: Dr D Narasiman, Center for Floristic Research, Department of Botany, Madras Christian College, Chennai, Tamilnadu, India for identifying the plant sample and thank the IGCAR (Indira Gandhi Centre for Atomic Research) for the SEM analysis of the nanoparticles.

\section{Disclosure}

The authors report no conflicts of interest in this work.

\section{References}

1. Ankamwar B, Chaudhary M, Sastry M. Gold Nanotriangles biologically synthesized using tamarind leaf extract and potential application in vapor sensing. Synthesis and Reactivity in Inorganic, Metal-Organic, and Nano-Metal Chemistry. 2005;35(1):19-26.

2. Antony JJ, Sivalingam P, Siva D, et al. Comparative evaluation of antibacterial activity of silver nanoparticles synthesized using Rhizophora apiculata and glucose. Colloids Surf B Biointerfaces. 2011;88(1):134-140.

3. Castro L, Blázquez ML, González F, Muñoz JA, Ballester A. Extracellular biosynthesis of gold nanoparticles using sugar beet pulp. Chemical Engineering Journal. 2010;164(1):92-97.

4. Cruz D, Falé PL, Mourato A, Vaz PD, Serralheiro ML, Lino AR. Preparation and physicochemical characterization of ag nanoparticles biosynthesized by Lippia citriodora (Lemon Verbena). Colloids Surf B Biointerfaces. 2010;81(1):67-73.

5. Elavazhagan T, Arunachalam KD. Memecylon edule leaf extract mediated green synthesis of silver and gold nanoparticles. Int J Nanomedicine. 2011;6:1265-1278.

6. Monteiro JM, Vollú RE, Coelho MRR, Fonseca A, Gomes Neto SC, Seldin L. Bacterial communities within the rhizosphere and roots of vetiver (Chrysopogon zizanioides (L) Roberty) sampled at different growth stages. European Journal of Soil Biology. 2011;47:236-242. http://dx.doi.org/10.1016/j.ejsobi.2011.05.006.

7. Husain A, Sharma JR, PH, TB. Genetic Resources of Important Medicinal and Aromatic Plants in South Asia-A Status Report for IBPGR, Rome. 1986;1-350.

8. Panel on Vetiver, Board on Science and Technology for International Development, National Research Council. Vetiver Grass: A Thin Green Line Against Erosion. Washington, DC: National Academy Press; 1993.

9. Dar MA, Ingle A, Rai M. Enhanced antimicrobial activity of silver nanoparticles synthesized by Cryphonectria sp evaluated singly and in combination with antibiotics. Nanomedicine. 2013;9(1):105-110.

10. Khan Z, Singh T, Hussain JI, Obaid AY, Al-Thabaiti SA, E1Mossalamy EH. Starch-directed green synthesis, characterization and morphology of silver nanoparticles. Colloids Surf B Biointerfaces. 2013;102:578-584.

11. Khalil MMH, Ismail EH, El-Magdoub F. Biosynthesis of Au nanoparticles using olive leaf extract: 1st Nano Updates. Arabian Journal of Chemistry. 2012;5(4):431-437.
12. MubarakAli D, Thajuddin N, Jeganathan K, Gunasekaran M. Plant extract mediated synthesis of silver and gold nanoparticles and its antibacterial activity against clinically isolated pathogens. Colloids Surf B Biointerfaces. 2011;85(2):360-365.

13. Arunachalam KD, Annamalai SK, Hari S. One-step green synthesis and characterization of leaf extract-mediated biocompatible silver and gold nanoparticles from Memecylon umbellatum. Int J Nanomedicine. 2013;8:307-1315.

14. Parekh J, Chanda SV. In vitro antimicrobial activity and phytochemical analysis of some Indian medicinal plants. Turk $J$ Biol. 2007;31:53-58.

15. Arunachalam KD, Subhashini S, Annamalai SK. Wound healing and antigenotoxic activities of Aegle marmelos with relation to its antioxidant properties. J Pharm Res. 2012;5(3):1492-1502.

16. Guruvaiah P, Arunachalam A, Velan LPT. Evaluation of phytochemical constituents and antioxidant activities of successive solvent extracts of leaves of Indigofera caerulea Roxb using various in vitro antioxidant assay systems. Asian Pacific Journal of Tropical Disease. 2012;2(Suppl 1): S118-S123.

17. Von White G, Kerscher P, Brown RM, et al. Green synthesis of robust, biocompatible silver nanoparticles using garlic extract. J Nanomater. 2012;2012:1-12.

18. Shankar SS, Rai A, Ahmad A, Sastry M. Rapid synthesis of Au, $\mathrm{Ag}$, and bimetallic Au core-Ag shell nanoparticles using Neem (Azadirachta indica) leaf broth. J Colloid Interface Sci. 2004;275(2): 496-502.

19. Shameli K, Ahmad MB, Zamanian A, et al. Green biosynthesis of silver nanoparticles using Curcuma longa tuber powder. Int J Nanomedicine. 2012;7:5603-5610.

20. Raut RW, Lakkakula JR, Kolekar NS, Mendhulkar VD, Kashid SB. Photosynthesis of silver nanoparticle using gliricidia sepium (Jacq). Curr Nanosci. 2009;5:117-122.

21. Sathishkumar M, Sneha K, Won SW, Cho CW, Kim S, Yun YS. Cinnamon zeylanicum bark extract and powder mediated green synthesis of nano-crystalline silver particles and its bactericidal activity. Colloids Surf B Biointerfaces. 2009;73(2): 332-338.

22. Usha RP, Rajasekharreddy P. Green-Green synthesis of silver-protein (core-shell) nanoparticles using Piper betle L leaf extract and its ecotoxicological studies on Daphnia magna. Colloids Surf A Physicochem Eng Asp. 2011;389(1-3):188-194.

23. Yi Z, Li X, Xu X, et al. Green, effective chemical route for the synthesis of silver nanoplates in tannic acid aqueous solution. Colloids Surf A Physicochem Eng Asp. 2011;392(1):131-136.

24. Dipankar C, Murugan S. The green synthesis, characterization and evaluation of the biological activities of silver nanoparticles synthesized from Iresine herbstii leaf aqueous extracts. Colloids Surf B Biointerfaces. 2012;98:112-119.

25. Darroudi M, Ahmad MB, Zamiri R, Zak AK, Abdullah AH, Ibrahim NA. Time-dependent effect in green synthesis of silver nanoparticles. Int $J$ Nanomedicine. 2011;6:677-81.

26. Dwivedi AD, Gopal K. Biosynthesis of silver and gold nanoparticles using Chenopodium album leaf extract. Colloids Surf A Physicochem Eng Asp. 2010;369(1-3):27-33.

27. Narayanan KB, Sakthivel N. Coriander leaf mediated biosynthesis of gold nanoparticles. Mater Lett. 2008;62(30):4588-4590.

28. Narayanan KB, Sakthivel N. Synthesis and characterization of nanogold composite using Cylindrocladium floridanum and its heterogeneous catalysis in the degradation of 4-nitrophenol. J Hazard Mater. 2011;189(1-2):519-525.

29. Boulc'h F, Schouler MC, Donnadieu P, Chaix JM, Djurado E. Domain size distribution of Y-TZP nano-particles using XRD and HRTEM. Image Anal Stereol. 2001;20:157-161.

30. Narayanan KB, Sakthivel N. Green synthesis of biogenic metal nanoparticles by terrestrial and aquatic phototrophic and heterotrophic eukaryotes and biocompatible agents. Adv Colloid Interface Sci. 2011;169(2):59-79. 
31. Shameli K, Ahmad MB, Zargar M, Yunus WM, Rustaiyan A, Ibrahim NA. Synthesis of silver nanoparticles in montmorillonite and their antibacterial behavior. Int J Nanomedicine. 2011;6:581-590.

32. Noruzi M, Zare D, Khoshnevisan K, Davoodi D. Rapid green synthesis of gold nanoparticles using Rosa hybrida petal extract at room temperature. Spectrochim Acta A Mol Biomol Spectrosc. 2011;79(5): 1461-1465.

33. Singh S, Saikia JP, Buragohain AK. A novel 'green' synthesis of colloidal silver nanoparticles (SNP) using Dillenia indica fruit extract. Colloids Surf B Biointerfaces. 2013;102:83-85.

34. Darroudi M, Ahmad MB, Abdullah AH, Ibrahim NA. Green synthesis and characterization of gelatin-based and sugar-reduced silver nanoparticles. Int J Nanomedicine. 2011;6:569-574.

35. Lu R, Yang D, Cui D, Wang Z, Guo L. Egg white-mediated green synthesis of silver nanoparticles with excellent biocompatibility and enhanced radiation effects on cancer cells. Int J Nanomedicine. 2012;7: 2101-2107.

36. Ravindran A, Chandran P, Khan SS. Biofunctionalized silver nanoparticles: advances and prospects. Colloids Surf B Biointerfaces. 2013;105:342-352.

37. Jagajjanani Rao K, Paria S. Green synthesis of silver nanoparticles from aqueous Aegle marmelos leaf extract. Mater Res Bull. 2013;48(2): $628-634$.

38. Logeswari P, Silambarasan S, Abraham J. Synthesis of silver nanoparticles using plants extract and analysis of their antimicrobial property. Journal of Saudi Chemical Society. [Epub May 1, 2012.]

39. Narayanan KB, Sakthivel N. Facile green synthesis of gold nanostructures by NADPH-dependent enzyme from the extract of Sclerotium rolfsii. Colloids Surf A Physicochem Eng Asp. 2011;380(1-3):156-161.

40. Vijayaraghavan K, Nalini SP, Prakash NU, Madhankumar D. One step green synthesis of silver nano/microparticles using extracts of Trachyspermum ammi and Papaver somniferum. Colloids Surf B Biointerfaces. 2012;94:114-117.
41. Bar H, Bhui DK, Sahoo GP, Sarkar P, De SP, Misra A. Green synthesis of silver nanoparticles using latex of Jatropha curcas. Colloids Surf A Physicochem Eng Asp. 2009;339(1-3):134-139.

42. Ghosh S, Patil S, Ahire M, et al. Synthesis of silver nanoparticles using Dioscorea bulbifera tuber extract and evaluation of its synergistic potential in combination with antimicrobial agents. Int J Nanomedicine. 2012;7:483-496.

43. Khan Z, Hussain JI, Hashmi AA. Shape-directing role of cetyltrimethylammonium bromide in the green synthesis of Ag-nanoparticles using Neem (Azadirachta indica) leaf extract. Colloids Surf B Biointerfaces. 2012;95:229-234.

44. Shukla VK, Singh RP, Pandey AC. Black pepper assisted biomimetic synthesis of silver nanoparticles. J Alloys Compd. 2010;507(1): L13-L16.

45. Jin G, Prabhakaran MP, Kai D, Annamalai SK, Arunachalam KD, Ramakrishna S. Tissue engineered plant extracts as nanofibrous wound dressing. Biomaterials. 2013;34(3):724-734.

46. Arunachalam KD, Annamalai SK, Arunachalam AM, Subashini K. Green synthesis of crystalline silver nanoparticles using indigofera aspalathoides - medicinal plant extract for wound healing applications. Asian Journal of Chemistry. 2013. http://www.scopus.com/inward/ record.url?eid=2-s2.0-84878297285\&partnerID $=40 \& \mathrm{md} 5=\mathrm{bcb} 42 \mathrm{a} 08$ $725734 \mathrm{fb} 4266055 \mathrm{e} 8 \mathrm{e} 6384 \mathrm{~d} 3$

47. Kumar KP, Paul W, Sharma CP. Green synthesis of gold nanoparticles with Zingiber officinale extract: characterization and blood compatibility. Process Biochemistry. 2011;46(10):2007-2013.

48. Meenakumari S, Arunachalam KD and Kumar AS. (2013). Screening and characterisation of silver nanoparticles for the prevention of biofilm in urinary catheters. Asian Journal of Chemistry, 25(SUPPL), S347-S349.
International Journal of Nanomedicine

\section{Publish your work in this journal}

The International Journal of Nanomedicine is an international, peerreviewed journal focusing on the application of nanotechnology in diagnostics, therapeutics, and drug delivery systems throughout the biomedical field. This journal is indexed on PubMed Central, MedLine, CAS, SciSearch $\AA$, Current Contents ${ }^{\circledR} /$ Clinical Medicine,

\section{Dovepress}

Journal Citation Reports/Science Edition, EMBase, Scopus and the Elsevier Bibliographic databases. The manuscript management system is completely online and includes a very quick and fair peer-review system, which is all easy to use. Visit http://www.dovepress.com/ testimonials.php to read real quotes from published authors. 